\title{
Changes in ISO 15653-Based CTOD for Specimens of $a_{0} / W=0.45 *$
}

\author{
Yoichi KAYAMORI**, Takehiro INOUE** and Tetsuya TAGAWA*** \\ ** Steel Research Laboratories, Nippon Steel Corporation \\ 20-1 Shintomi, Futtsu, Chiba, 293-8522 Japan \\ E-mail: kayamori.yoichi@nsc.co.jp \\ *** Graduate School of Engineering, Osaka University \\ 2-1 Yamada-Oka, Suita, Osaka, 565-0871 Japan
}

\begin{abstract}
ISO 15653 is a Crack Tip Opening Displacement (CTOD) testing standard for welds, and has issued since 2010. This new testing standard consists of two different CTOD calculations, displacement-conversion CTOD for deep-notched specimens and J-conversion CTOD for shallow-notched specimens, and ISO 15653-based CTOD changes at the boundary of crack length between deep-notched and shallow-notched specimens. In this study, changes in ISO 15653-based CTOD were investigated by using experimental and analytical data for the wide range of steel mechanical properties. J-conversion CTOD did not correspond to displacement-conversion CTOD, and there were significant mismatches in ISO 15653-based CTOD at the crack length boundary particularly for the steels of the low strain hardening exponent of the Ramberg-Osgood relation. Displacement-conversion CTOD calculation by using the modified plastic rotational factor or using the CTOD transformation equation proposed in this study is helpful in moderating the underestimated CTOD for low strain hardening exponent shallow-notched specimens.
\end{abstract}

Key words: CTOD, J-Integral, Elastic-Plastic Fracture, Fracture Toughness, Shallow-Notched Specimen, Testing Standard, ISO

\section{Introduction}

CTOD has been widely used as an elastic-plastic fracture mechanics parameter for structural steel. CTOD fracture toughness testing was initially standardized by the British Standards Institution in BS5762 $2^{(1)}$, which was replaced by BS7448 ${ }^{(2)}$, and was extended to other CTOD testing standards such as ASTM E1290 ${ }^{(3)}$ and WES1108 ${ }^{(4)}$. These standards conventionally assume the plastic hinge model, and a few constant plastic rotational factors are used for converting Crack Mouth Opening Displacement (CMOD) into the plastic component of CTOD. On the other hand, the normalized crack length and the strain hardening exponent affect the plastic rotational factor ${ }^{(5)(6)}$, and this is disadvantageous to the accurate calculation of CTOD. ASTM International revised E1290 in $2002^{(7)}$, and its latest edition was issued in $2008^{(8)}$, where CTOD was not calculated by using the plastic hinge model, but was converted from J-integral. Because structural steel qualifications such as API RP2Z ${ }^{(9)}$ and DNV-OS-C401 ${ }^{(10)}$ have essentially required fracture toughness in accordance with CTOD tests using the plastic hinge model, a discrepancy between two different kinds of CTOD, conventional displacement-conversion CTOD and new J-conversion CTOD, should be avoided. 
Table 1 CTOD testing standard comparison

\begin{tabular}{|c|c|c|c|c|}
\hline \multicolumn{2}{|c|}{ Standard } & Year & CTOD & $\begin{array}{c}\text { Initial normalized } \\
\text { crack length }\end{array}$ \\
\hline \multicolumn{2}{|c|}{ BS7448: Part 1} & 1991 & Displacement-conversion & $0.45 \leq a_{0} / W \leq 0.55$ \\
\hline \multicolumn{2}{|c|}{ WES1108 } & 1995 & Displacement-conversion & $0.45 \leq a_{0} / W \leq 0.55$ \\
\hline \multicolumn{2}{|c|}{ ASTM E1290 } & 2008 & J-conversion & $0.45 \leq a_{0} / W \leq 0.70$ \\
\hline \multicolumn{2}{|c|}{ ISO 12135} & 2002 & Displacement-conversion & $0.45 \leq a_{0} / W \leq 0.70$ \\
\hline \multirow[b]{2}{*}{ ISO 15653} & Normative & 2010 & Displacement-conversion & $0.45 \leq a_{0} / W \leq 0.70$ \\
\hline & $\begin{array}{c}\text { Annex E } \\
\text { (informative) }\end{array}$ & 2010 & J-conversion & $0.10 \leq a_{0} / W \leq 0.45$ \\
\hline
\end{tabular}

The International Organization for Standardization (ISO), which promulgates worldwide industrial and commercial standards, has set a CTOD testing standard of ISO $12135^{(11)}$ for deep-notched bend specimens since 2002, where CTOD is displacement-conversion and determined by using the plastic hinge model. In addition, ISO has issued another CTOD testing standard of ISO $15653^{(12)}$ specially for welds since 2010 . This new CTOD testing standard consists of a normative test method for a deep-notched bend specimen of $0.45 \leq a_{0} / W \leq 0.70$ and an informative test method in Annex E for a shallow-notched bend specimen of $0.10 \leq a_{0} / W \leq 0.45$, as shown in Table 1 , where $a_{0}$ is the initial crack length and $W$ is the specimen width. Although CTOD in ISO 15653 is displacement-conversion for deep-notched specimens, it is J-conversion for shallow-notched specimens; both CTODs are available for a specimen of $a_{0} / W=0.45$. However, it has been unclear whether two different CTOD calculations result in the identical value of CTOD for a specimen of $a_{0} / W=0.45$. The authors previously investigated the relationship between displacement-conversion CTOD and J-conversion CTOD for deep-notched ${ }^{(13)-(15)}$ and shallow-notched ${ }^{(16)}$ specimens, and demonstrated that J-conversion CTOD was occasionally much lower than displacement-conversion CTOD for brittle fracture and the CTOD relationship was particularly affected by the strain hardening exponent. This suggests that there is a significant mismatch between two CTODs at $a_{0} / W=0.45$ in ISO 15653.

In this study, eighteen force vs. CMOD curves of deep-notched and shallow-notched specimens were referred to, and their critical CTOD values were calculated by using ISO 15653. Changes in ISO 15653-based CTOD were investigated at $a_{0} / W=0.45$ for the wide range of steel mechanical properties.

\section{Nomenclature}

$A$ : plastic area under the force versus crack mouth opening displacement curve

$a_{0}$ : initial crack length

$B:$ specimen thickness

$E$ : Young's modulus

$F:$ force

$F_{0}$ : reference force as the limit load in the EPRI scheme

$f_{1}, f_{2}$ : CTOD transformation factors

$h_{1}, h_{2}=$ factors in the EPRI scheme

$J_{0}:$ J-integral

$J_{0, \mathrm{el}}$ : elastic component of $J_{0}$

$J_{0, \mathrm{pl}}$ : plastic component of $J_{0}$

$K_{0}:$ stress intensity factor

$m$ : constraint factor 
$n$ : strain hardening exponent of the n-power hardening law

$N$ : strain hardening exponent of the Ramberg-Osgood relation

$R_{\mathrm{mb}}$ : tensile strength

$R_{\mathrm{p} 0.2 \mathrm{~b}}: 0.2 \%$ offset yield strength

$R_{\mathrm{Y}}$ : effective yield strength

$r_{\mathrm{pl}}:$ plastic rotational factor

$S:$ span in $\mathrm{SE}(\mathrm{B})$ specimens

$V_{\mathrm{pl}}$ : plastic component of crack mouth opening displacement

$W:$ specimen width

$z$ : distance of the knife edge measurement point from the front face

$\alpha:$ material factor in the plastic term of the Ramberg-Osgood relation

$\delta_{\text {disp }}:$ displacement-conversion CTOD

$\delta_{\text {disp,el }}$ : elastic component of $\delta_{\text {disp }}$

$\delta_{\text {disp,pl }}:$ plastic component of $\delta_{\text {disp }}$

$\delta_{\text {ISO15653 }}:$ ISO 15653 -based CTOD

$\delta_{\mathrm{J}}: \mathrm{J}$-conversion CTOD

$\delta_{\mathrm{J}, \mathrm{el}}:$ elastic component of $\delta_{\mathrm{J}}$

$\delta_{\mathrm{J}, \mathrm{pl}}:$ plastic component of $\delta_{\mathrm{J}}$

$\varepsilon:$ strain

$\varepsilon_{\mathrm{ys}}:$ yield strain

$\eta_{\mathrm{c}}:$ plastic J-calibration eta factor

$v$ : Poisson's ratio

$\sigma:$ stress

\section{Background of CTOD calculation}

\subsection{Displacement-conversion CTOD}

One kind of CTOD in ISO 15653 is the displacement-conversion CTOD, $\delta_{\text {disp}}$, for $0.45 \leq a_{0} / W \leq 0.70$, and is given by the following equation ${ }^{(12)}$, where $\delta_{\text {disp,el }}$ is the elastic part of $\delta_{\text {disp }}, \delta_{\text {disp,pl }}$ is the plastic part of $\delta_{\text {disp }}, K_{0}$ is the stress intensity factor, $v$ is Poisson's ratio, $E$ is Young's modulus, $R_{\mathrm{p} 0.2 \mathrm{~b}}$ is the $0.2 \%$ offset yield strength, $r_{\mathrm{pl}}$ is the plastic rotational factor, $V_{\mathrm{pl}}$ is the plastic part of CMOD, $a_{0}$ is the initial crack length and $z$ is the distance of the knife edge measurement point from the front face on Single Edge-notch Bend (SE(B)) specimens. The plastic hinge model is used for calculating $\delta_{\mathrm{disp}, \mathrm{pl}}$, and $r_{\mathrm{pl}}$ is set at 0.4 for $\mathrm{SE}(\mathrm{B})$ specimens.

$$
\begin{aligned}
\delta_{\text {disp }} & =\delta_{\text {disp,el }}+\delta_{\text {disp }, \mathrm{pl}} \\
& =\frac{K_{0}^{2}\left(1-v^{2}\right)}{2 R_{\mathrm{p} 0.2 \mathrm{~b}} E}+\frac{r_{\mathrm{pl}}\left(W-a_{0}\right) V_{\mathrm{pl}}}{r_{\mathrm{pl}}\left(W-a_{0}\right)+a_{0}+z}
\end{aligned}
$$

\subsection{J-conversion CTOD}

The other kind of CTOD in ISO 15653 is the J-conversion CTOD, $\delta_{\mathrm{J}}$, for $0.10 \leq a_{0} / W \leq 0.45$, and is given by the following equation ${ }^{(12)}$, where $J_{0}$ is the $\mathrm{J}$-integral, $R_{\mathrm{Y}}$ is the effective yield strength given by the average of $R_{\mathrm{p} 0.2 \mathrm{~b}}$ and the tensile strength, $R_{\mathrm{mb}}, \delta_{\mathrm{J}, \mathrm{el}}$ is the elastic part of $\delta_{\mathrm{J}}, \delta_{\mathrm{J}, \mathrm{pl}}$ is the plastic part of $\delta_{\mathrm{J}}, J_{0, \mathrm{el}}$ is the elastic part of $J_{0}, J_{0, \mathrm{pl}}$ is the plastic part of $J_{0}, A$ is the plastic area under the plot of force, $F$, versus CMOD and $B$ is the specimen thickness.

$$
\begin{aligned}
\delta_{\mathrm{J}} & =\frac{J_{0}}{m R_{\mathrm{Y}}} \\
& =\frac{1}{m R_{\mathrm{Y}}}\left(J_{0, \mathrm{el}}+J_{0, \mathrm{pl}}\right)
\end{aligned}
$$




$$
=\frac{1}{m R_{\mathrm{Y}}}\left[\frac{K_{0}{ }^{2}\left(1-v^{2}\right)}{E}+\frac{\eta_{\mathrm{c}} A}{B\left(W-a_{0}\right)}\right]
$$

$m$ and $\eta_{\mathrm{c}}$ are the constraint factor and the plastic J-calibration eta factor, respectively, and given by the following equations for $\mathrm{SE}(\mathrm{B})$ specimens.

$$
\begin{gathered}
m=A_{0}-A_{1}\left(\frac{R_{\mathrm{p} 0.2 \mathrm{~b}}}{R_{\mathrm{mb}}}\right)+A_{2}\left(\frac{R_{\mathrm{p} 0.2 \mathrm{~b}}}{R_{\mathrm{mb}}}\right)^{2}-A_{3}\left(\frac{R_{\mathrm{p} 0.2 \mathrm{~b}}}{R_{\mathrm{mb}}}\right)^{3} \\
A_{0}=3.18-0.22\left(\frac{a_{0}}{W}\right), \quad A_{1}=4.32-2.23\left(\frac{a_{0}}{W}\right) \\
A_{2}=4.44-2.29\left(\frac{a_{0}}{W}\right), \quad A_{3}=2.05-1.06\left(\frac{a_{0}}{W}\right) \\
\eta_{\mathrm{c}}=3.667-2.199\left(\frac{a_{0}}{W}\right)+0.437\left(\frac{a_{0}}{W}\right)^{2}
\end{gathered}
$$

\section{CTOD fracture toughness testing}

\subsection{CTOD test data}

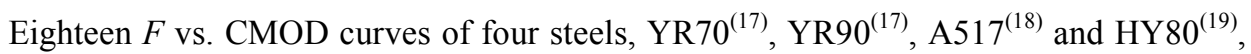
were referred to, and their mechanical properties and CTOD test conditions are shown in Table 2, where $S$ is the span of $\mathrm{SE}(\mathrm{B})$ specimens. $N$ is the strain hardening exponent of the Ramberg-Osgood relation denoted by the following equation, where $\varepsilon$ is the strain, $\varepsilon_{\mathrm{ys}}$ is the yield strain, $\sigma$ is the stress and $\alpha$ is the material factor in the plastic term.

$$
\frac{\varepsilon}{\varepsilon_{\mathrm{ys}}}=\frac{\sigma}{R_{\mathrm{p} 0.2 \mathrm{~b}}}+\alpha\left(\frac{\sigma}{R_{\mathrm{p} 0.2 \mathrm{~b}}}\right)^{N}
$$

$N$ is equivalent to the inverse of the strain hardening exponent of the $n$-power hardening law, $n$, and it can be estimated empirically from the following equation in ASTM E1290-02 $2^{(7)}$.

$$
\begin{aligned}
n & =\frac{1}{N} \\
& =1.724-6.098\left(\frac{R_{\mathrm{p} 0.2 \mathrm{~b}}}{R_{\mathrm{mb}}}\right)+8.326\left(\frac{R_{\mathrm{p} 0.2 \mathrm{~b}}}{R_{\mathrm{mb}}}\right)^{2}-3.965\left(\frac{R_{\mathrm{p} 0.2 \mathrm{~b}}}{R_{\mathrm{mb}}}\right)^{3}
\end{aligned}
$$

\begin{tabular}{|c|c|c|c|c|c|c|c|c|c|}
\hline \multirow{2}{*}{ Steel } & \multicolumn{3}{|c|}{$\begin{array}{l}\text { Mechanical properties } \\
\text { at CTOD test temp. }\end{array}$} & \multicolumn{5}{|c|}{ CTOD test conditions } & \multirow{2}{*}{ Ref. } \\
\hline & $\begin{array}{l}R_{\mathrm{p} 0.2 \mathrm{~m}} \\
(\mathrm{MPa})\end{array}$ & $\begin{array}{c}R_{\mathrm{mb}} \\
(\mathrm{MPa})\end{array}$ & $N$ & $\begin{array}{c}B \\
(\mathrm{~mm})\end{array}$ & $\begin{array}{c}W \\
(\mathrm{~mm})\end{array}$ & $\begin{array}{c}S \\
(\mathrm{~mm})\end{array}$ & $a_{0} / W$ & $\begin{array}{l}\text { Temp. } \\
\left({ }^{\circ} \mathrm{C}\right)\end{array}$ & \\
\hline YR70 & 612 & 794 & 6.47 & 15 & 30 & 120 & $0.3,0.5$ & -120 & $(17)$ \\
\hline YR90 & 776 & 825 & 18.1 & 15 & 30 & 120 & $0.3,0.5$ & -120 & (17) \\
\hline A517 & 834 & 924 & 11.4 & 25.4 & 25.4 & 102 & $0.17,0.5$ & -76 & (18) \\
\hline HY80 & 630 & 735 & 8.53 & 25.4 & 50.8 & 203 & $0.29 \sim 0.61$ & 21 & (19) \\
\hline
\end{tabular}

All the CTOD tests were conducted by using SE(B) specimens, and their $a_{0} / W$ ranged from 0.17 to 0.61 . The critical values of $\delta_{\text {disp }}$ and $\delta_{\mathrm{J}}$ were evaluated by Eqs. (1) and (2), respectively, where $r_{\mathrm{pl}}$ was modified for $a_{0} / W<0.45$ according to Kirk et al. ${ }^{(5)}$.

Table 2 Mechanical properties and CTOD test conditions 


\subsection{Results of ISO 15653-based CTOD calculation}

The relationships between the critical CTOD and $a_{0} / W$ are shown in Figs $1 \sim 4$, where the critical CTOD values were calculated for brittle fracture in YR70, YR90 and A517, and for plastic instability in HY80. Although the critical values of $\delta_{\text {disp }}$ and $\delta_{\mathrm{J}}$ were scattered in YR70 and YR90, they tend to increase with decreasing $a_{0} / W$. The number of CTOD test data was not numerous in A517 and HY80, but $\delta_{\text {disp }}$ and $\delta_{\mathrm{J}}$ obviously exhibited a rise in their critical values of shallow-notched specimens. There was a significant difference between $\delta_{\text {disp }}$ and $\delta_{\mathrm{J}}$ in each low $N$ steel, YR70 or HY80, while the difference between $\delta_{\text {disp }}$ and $\delta_{\mathrm{J}}$ was quite small in each high $N$ steel, YR90 or A517.

ISO 15653-based CTOD, $\delta_{\text {ISO15653 }}$, is $\delta_{\text {disp }}$ for $0.45 \leq a_{0} / W$, and is $\delta_{\mathrm{J}}$ for $a_{0} / W \leq 0.45$. The relationships between the critical $\delta_{\text {ISO15653 }}$ values and $a_{0} / W$ are also drawn in Figs $1 \sim 4$. The lines of CTOD discontinuity were recognized in $\delta_{\mathrm{ISO} 015653}$ at $a_{0} / W=0.45$, and the discontinuity was remarkable in YR70 and HY80; there was a significant mismatch of $\delta_{\mathrm{ISO} 15653}$ at $a_{0} / W=0.45$.

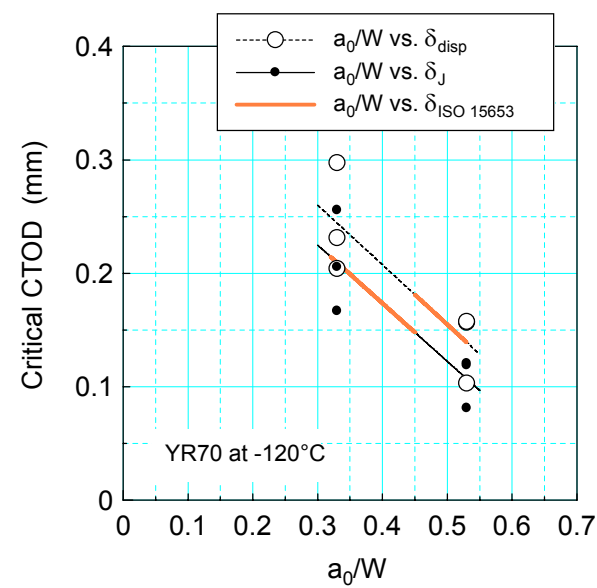

Fig. 1 ISO 15653-based critical CTOD variation with the normalized crack length in YR70

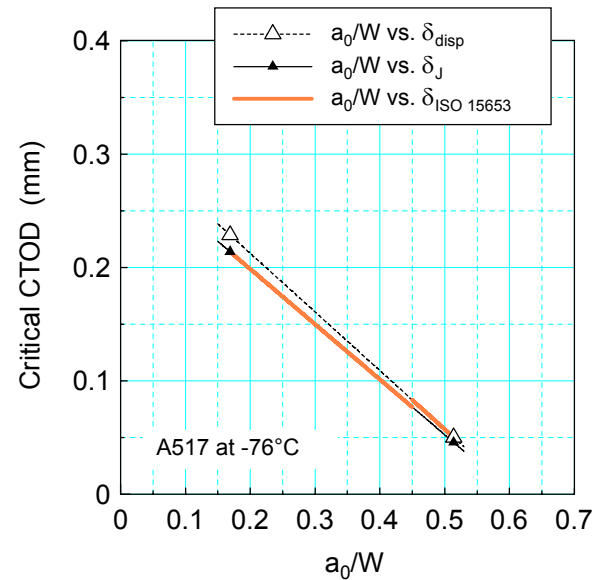

Fig. 3 ISO 15653-based critical CTOD variation with the normalized crack length in A517

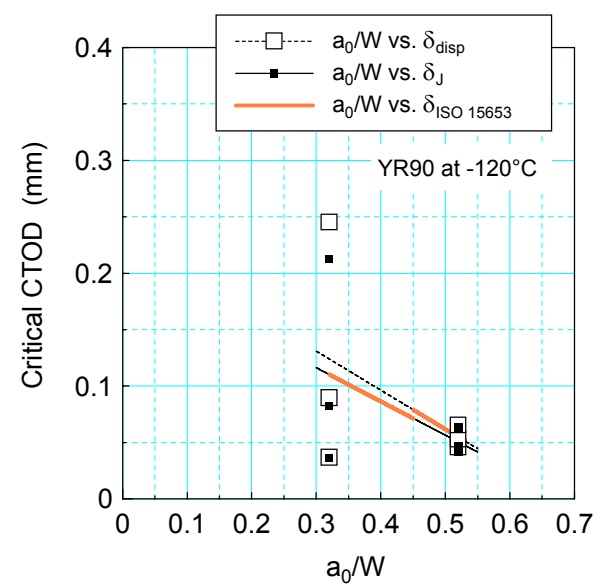

Fig. 2 ISO 15653-based critical CTOD variation with the normalized crack length in YR90

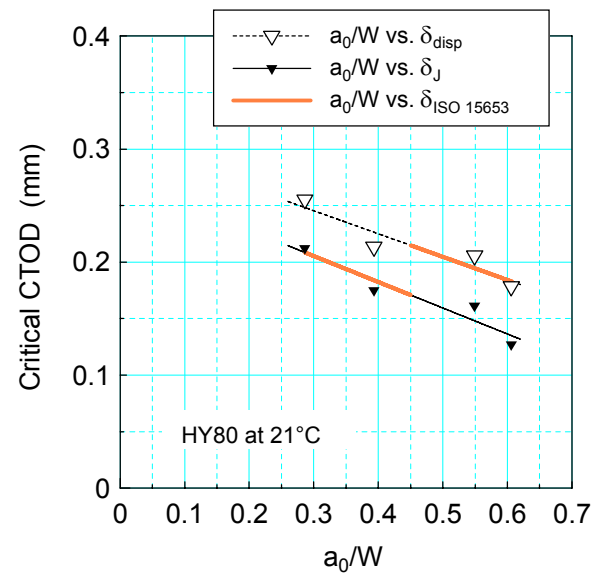

Fig. 4 ISO 15653-based critical CTOD variation with the normalized crack length in HY80 
Table 3 Analytical conditions

\begin{tabular}{|c|c|c|c|c|}
\hline \multicolumn{2}{|c|}{ Mechanical properties } & \multicolumn{3}{c|}{ Specimen } \\
\hline$R_{\mathrm{p} 0.2 \mathrm{~b}}(\mathrm{MPa})$ & $N$ & $a_{0} / W$ & $B(\mathrm{~mm})$ & Configuration \\
\hline $300,600,900$ & $5,10,16$ & 0.45 & 25.4 & SE(B) \\
\hline
\end{tabular}

\section{CTOD analysis}

\subsection{Analytical methodology}

The Electric Power Research Institute (EPRI) scheme ${ }^{(20)}$ was used for the calculation of $J_{0, \mathrm{pl}}$ and $V_{\mathrm{pl}}$ in the following equations, where $F_{0}$ is the limit load of $\mathrm{SE}(\mathrm{B})$ specimens.

$$
\begin{aligned}
& J_{0, \mathrm{pl}}=\alpha \varepsilon_{\mathrm{ys}} R_{\mathrm{p} 0.2 \mathrm{~b}}\left(W-a_{0}\right) h_{1}\left(\frac{F}{F_{0}}\right)^{N+1} \\
& V_{\mathrm{pl}}=\alpha \varepsilon_{\mathrm{ys}} a_{0} h_{2}\left(\frac{F}{F_{0}}\right)^{N} \\
& F_{0}=\frac{1.455 B\left(W-a_{0}\right)^{2} R_{\mathrm{p} 0.2 \mathrm{~b}}}{S}
\end{aligned}
$$

$h_{1}$ and $h_{2}$ are factors, which relate to $a_{0} / W, N$, specimen configuration and constraint conditions, and are listed in the EPRI report ${ }^{(20)} . \delta_{\text {disp }}$ and $\delta_{\mathrm{J}}$ were analytically obtained by substituting $V_{\mathrm{pl}}$ of Eq. (8) into Eq. (1) and by substituting $J_{0, \mathrm{pl}}$ of Eq. (7) into Eq. (2), respectively ${ }^{(13)}$. Table 3 shows the analytical conditions used in this analysis. $R_{\mathrm{p} 0.2 \mathrm{~b}}$ and $N$ were widely arranged from $300 \mathrm{MPa}$ to $900 \mathrm{MPa}$ and 5 to 16 , respectively.

\subsection{Results of ISO 15653-based CTOD analysis}

Figure 5 shows the relationships between $\delta_{\mathrm{J}} / \delta_{\text {disp }}$ and $F / F_{0}$, in which $a_{0} / W$ and $N$ were set at 0.45 and 5 , respectively, and three different $R_{\mathrm{p} 0.2 \mathrm{~b}}$ values were used for the analysis. Although low $R_{\mathrm{p} 0.2 \mathrm{~b}}$ steel gave slightly lower $\delta_{\mathrm{J}} / \delta_{\text {disp }}$, three curves were closely located in the part of $\delta_{\mathrm{J}} / \delta_{\text {disp }}<1 . \delta_{\mathrm{J}} / \delta_{\text {disp }}$ was not constant, but changed according to $F / F_{0}$. The minimum $\delta_{\mathrm{J}} / \delta_{\text {disp }}$ value was 0.668 at $F / F_{0}=0.90$ for the mechanical model of $R_{\mathrm{p} 0.2 \mathrm{~b}}=300 \mathrm{MPa}$. Three curves of $\delta_{\mathrm{J}} / \delta_{\text {disp }}$ vs. $F / F_{0}$ are shown in Fig. 6 , in which $a_{0} / W$ and $R_{\mathrm{p} 0.2 \mathrm{~b}}$ were set at 0.45 and $600 \mathrm{MPa}$, respectively, and three different $N$ values were used for the analysis. $\delta_{\mathrm{J}} / \delta_{\text {disp }}$ was reduced with decreasing $N$, and $\delta_{\mathrm{J}} / \delta_{\text {disp }}$ was smaller than 1 for $N=5$. However, the curves of $\delta_{\mathrm{J}} / \delta_{\text {disp }}$ vs. $F / F_{0}$ were located in the part of $\delta_{\mathrm{J}} / \delta_{\text {disp }}>1$ for $N=10$ and 16.

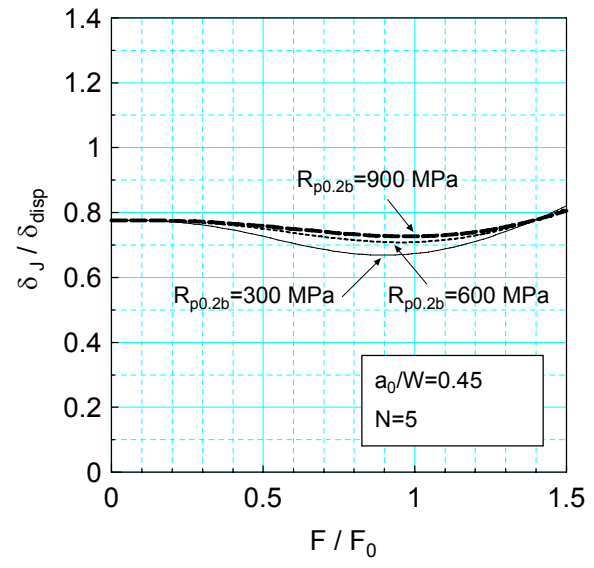

Fig. 5 Relationships between the ratio of J-conversion CTOD to displacementconversion CTOD and the normalized force in three different $0.2 \%$ offset yield strength models

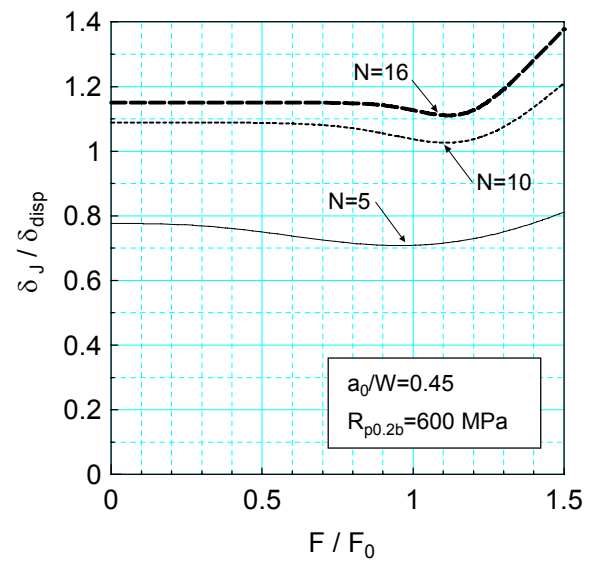

Fig. 6 Relationships between the ratio of J-conversion CTOD to displacementconversion CTOD and the normalized force in three different strain hardening exponent models 


\section{Discussion}

\subsection{Changes in ISO 15653-Based CTOD at $a_{0} / W=0.45$}

As shown in Figs $1 \sim 4$, both the critical $\delta_{\text {disp }}$ and the critical $\delta_{\mathrm{J}}$ increased with decreasing $a_{0} / W$. This is fundamentally caused by the loss of constraint ${ }^{(21)}$. In addition, the critical $\delta_{\mathrm{J}}$ did not correspond to the critical $\delta_{\text {disp }}$, and the critical $\delta_{\mathrm{J}}$ was particularly smaller than the critical $\delta_{\text {disp }}$ in low $N$ steels such as YR70 and HY80. This is probably because $\delta_{\mathrm{J}} / \delta_{\text {disp }}$ is highly affected by $N$, as shown in Fig 6 , and the critical $\delta_{\mathrm{ISO} 15653}$ was conspicuously discontinuous at $a_{0} / W=0.45$ in YR70 and HY 80 .

ISO 15653 uses two different CTODs, $\delta_{\text {disp }}$ and $\delta_{\mathrm{J}}$, but one kind of CTOD should be consistently utilized for qualification; almost all the CTOD requirements are originally prescribed in the critical $\delta_{\text {disp }}$ values ${ }^{(9)(10)}$. In addition, changes in CTOD from one to the other at $a_{0} / W=0.45$ make it difficult to show the effect of $a_{0} / W$ on the critical CTOD in low $N$ steels; although the critical $\delta_{\text {disp }}$ increased with decreasing $a_{0} / W$ on average, the critical $\delta_{\text {ISO15653 }}$ of $a_{0} / W=0.39$ was lower than those of $a_{0} / W=0.55$ and $a_{0} / W=0.61$ in HY80, as shown in Fig. 4. In other words, $\delta_{\mathrm{ISO} 15653}$ for shallow-notched specimens underestimates the critical CTOD. ISO 15653 does not use $\delta_{\text {disp }}$ for shallow-notched specimens, but the nominal $\delta_{\text {disp }}$ can be calculated for shallow-notched specimens by using $r_{\mathrm{pl}}$ modified for $a_{0} / W<0.45$, as conducted in this study. Another way of calculation $\delta_{\text {disp }}$ is the transformation of $\delta_{\mathrm{J}}$ into $\delta_{\text {disp. }}$.

\subsection{Transformation of $\delta_{\mathrm{J}}$ into $\delta_{\text {disp }}$}

The authors ${ }^{(13)}$ constructed an equation of the transformation of $\delta_{\text {disp }}$ to $\delta_{\mathrm{J}}$, and it was demonstrated that the transformation equation is reasonably accurate ${ }^{(16)}$ for shallow-notched specimens whose $a_{0} / W$ is within the valid range of in the EPRI scheme. Inversely, the following equation can transform $\delta_{\mathrm{J}}$ into $\delta_{\text {disp }}$ for the shallow-notched specimens.

$$
\begin{aligned}
\delta_{\text {disp }} & =\frac{1}{f_{1}}\left(\delta_{\text {J,el }}+\frac{1}{f_{2}} \frac{F_{0}}{F} \delta_{\text {J,pl }}\right) \\
f_{1} & =\frac{2 R_{\mathrm{p} 0.2 \mathrm{~b}}}{m R_{\mathrm{Y}}}, \quad f_{2}=\frac{h_{1}\left[r_{\mathrm{pl}}\left(W-a_{0}\right)+a_{0}+z\right]}{2 r_{\mathrm{pl}} a_{0} h_{2}}
\end{aligned}
$$

The critical $\delta_{\mathrm{J}}$ was transformed into the critical $\delta_{\text {disp }}$ by using Eq. (10), and shown in Figs $7 \sim 10$. The transformed critical $\delta_{\text {disp }}$ values were close to the original critical $\delta_{\text {disp }}$

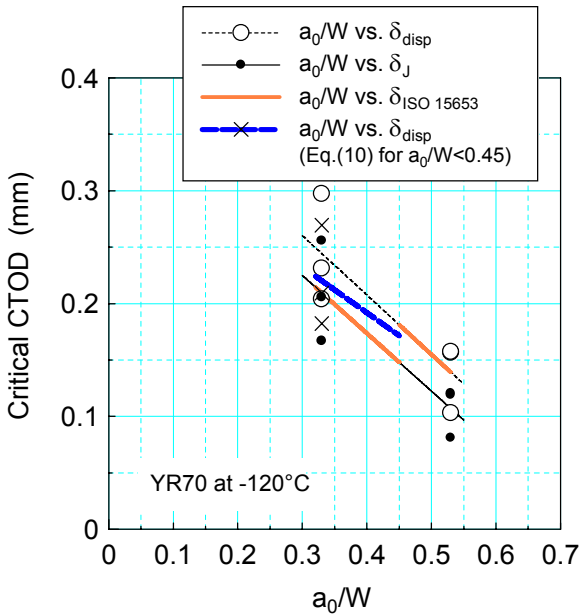

Fig. 7 Transformed critical displacementconversion CTOD and the ISO 15653-based critical CTOD variations with the normalized crack length in YR70

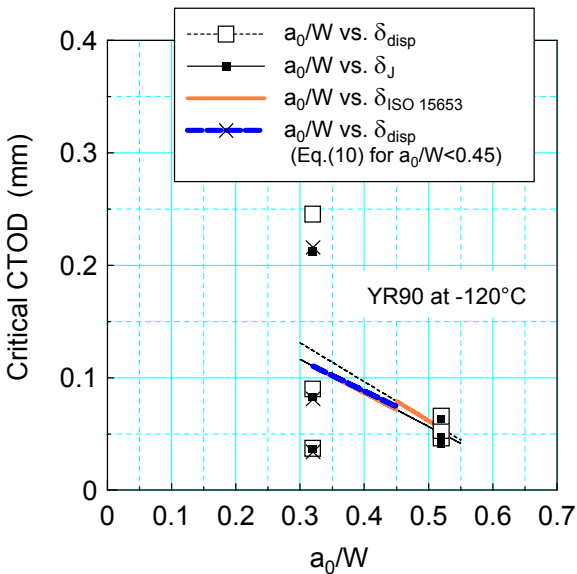

Fig. 8 Transformed critical displacementconversion CTOD and the ISO 15653-based critical CTOD variations with the normalized crack length in YR90 


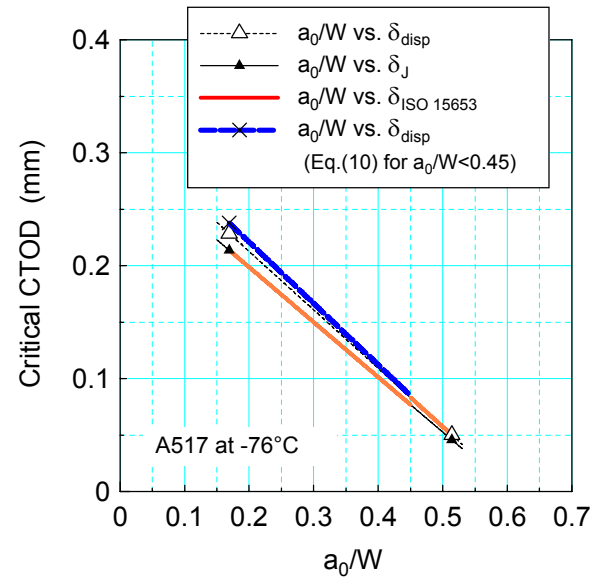

Fig. 9 Transformed critical displacementconversion CTOD and the ISO 15653-based critical CTOD variations with the normalized crack length in A517

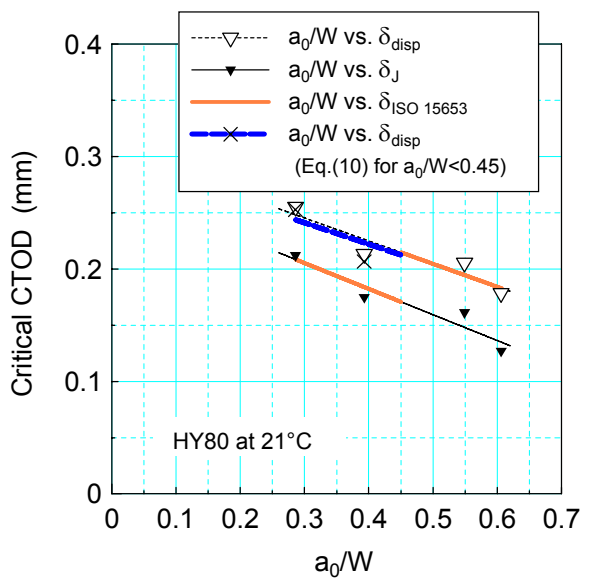

Fig. 10 Transformed critical displacementconversion CTOD and the ISO 15653-based critical CTOD variations with the normalized crack length in HY80

values in YR70 and HY80, and Eq. (10) is useful for moderating the underestimated CTOD for shallow-notched specimens. On the other hand, the transformed critical $\delta_{\text {disp }}$ was almost invariable in YR90 and A517 because $\delta_{\mathrm{J}}$ is essentially close to $\delta_{\text {disp }}$ for high $N$ steels.

In this study, CTOD test data used for the experimental investigation into ISO 15653-based CTOD change at $a_{0} / W=0.45$ were limited; four kinds of steel were referred to the investigation. The effects of mechanical properties, specimen sizes, test temperatures and applied forces on the CTOD change should be experimentally investigated in detail in the future.

\section{Concluding remarks}

In this study, ISO 15653-based CTOD was investigated by using experimental and analytical data. According to two different CTOD calculations in ISO 15653, there were significant mismatches in ISO 15653 -based CTOD at $a_{0} / W=0.45$ particularly for the steels of the low strain hardening exponent of the Ramberg-Osgood relation. Displacement-conversion CTOD calculation by using the modified plastic rotational factor or using the CTOD transformation equation proposed in this study is helpful in moderating the underestimated CTOD for shallow-notched specimens.

\section{Acknowledgement}

The authors would like to acknowledge the members of the Fracture Toughness Evaluation Committee of the Japan Welding Engineering Society.

\section{References}

(1) British Standards Institution, Methods for Crack Opening Displacement (COD) Testing, BS5762 (1979).

(2) British Standards Institution, Fracture Mechanics Toughness Tests. Method for Determination of $K_{I C}$, Critical CTOD and Critical J Values of Metallic Materials, BS7448-1 (1991). 
(3) ASTM International, Standard Test Method for Crack-Tip Opening Displacement (CTOD) Fracture Toughness Measurement, ASTM E1290 (1989).

(4) The Japan Welding Engineering Society, Standard Test Method for Crack-Tip Opening Displacement (CTOD) Fracture Toughness Measurement, WES1108 (1995).

(5) Kirk M. T. and Dodds R. H. Jr., J and CTOD Estimation Equations for Shallow Cracks in Single Edge Notch Bend Specimens, Journal of Testing and Evaluation, Vol. 21 No.4 (1993), pp. 228-238.

(6) Donato G. H. B. and Ruggieri C., Estimation Procedure for J and CTOD Fracture Parameters Using Three-Point Bend Specimens, Proceedings of the 6th International Pipeline Conference, IPC2006-10165 (2006-09), pp.1-9.

(7) ASTM International, Standard Test Method for Crack-Tip Opening Displacement (CTOD) Fracture Toughness Measurement, ASTM E1290 (2002).

(8) ASTM International, Standard Test Method for Crack-Tip Opening Displacement (CTOD) Fracture Toughness Measurement, ASTM E1290 (2008).

(9) American Petroleum Institute, Recommended Practice for Preproduction Qualification for Steel Plates for Offshore Structures, API RP2Z (2005).

(10) Det Norske Veritas, Fabrication and Testing of Offshore Structures, DNV-OS-C401 (2007).

(11) International Organization for Standardization, Metallic Materials - Unified Method of Test for the Determination of Quasistatic Fracture Toughness, ISO 12135 (2002).

(12) International Organization for Standardization, Metallic Materials - Method of Test for the Determination of Quasistatic Fracture Toughness of Welds, ISO 15653 (2010).

(13) Kayamori Y., Inoue T. and Tagawa T, Transformation of BS7448-CTOD to ASTM E1290-CTOD, Journal of Pressure Vessel Technology, Vol.132 No.4 (2010), pp.041401_1-7.

(14) Tagawa T., Kayamori Y., Ohata M., Handa T., Kawabata T., Yamashita Y., Tsutsumi K., Yoshinari H., Aihara S. and Hagihara Y., Comparison of CTOD Standards: BS 7448-Part 1 and Revised ASTM E1290, Engineering Fracture Mechanics, Vol.77 Issue2 (2010), pp.327-336.

(15) Kayamori Y., Inoue T. and Tagawa T., A Proposal for Two Characteristic Ratios of ASTM-CTOD to BS-CTOD, Materials Science Forum, Vols.638-642 (2010), pp.3852-3857.

(16) Kayamori Y., Inoue T. and Tagawa T., A Comparison of CMOD-Based CTOD and J-Conversion CTOD in Shallow Crack Specimens, Key Engineering Materials, Vols.452-453 (2011), pp.769-772.

(17) Matsuo T., Effect of Strain Hardening on Stress-Strain behavior and Critical Fracture of Notched Steel (in Japanese), MEng Thesis, Osaka University, Japan (1991).

(18) Smith J. A. and Rolfe S. T., The Effect of Crack Depth to Specimen Width Ratio on the Elastic-Plastic Fracture Toughness of a High-Strength Low-Strain Hardening Steel, WRC Bulletin, No.358 (1990), pp.1-19.

(19) Zhu X. K., Lies B. N. and Joyce J. A., Experimental Estimation of J-R Curves from Load-CMOD Record for SE(B) specimens, ASTM STP 1508, (2008), pp.66-86.

(20) Kumar V., German M. D. and Shih C. F., An Engineering Approach for Elastic-Plastic Fracture Analysis, EPRI NP-1931, (1981).

(21) Kirk M. T., Koppenhoefer K. C. and Shih C. F., Effect of Constraint on Specimen Dimensions Needed to obtain Structurally Relevant Toughness Measures, ASTM STP 1171, (1993), pp.79-103. 